\title{
Jeotgalibacillus kunyuensis sp. nov., a novel orange-pigmented species with relative genes or gene clusters, isolated from wetland soil in Yantai, China
}

Hui-Ning Jiang

Shuai-Ting Yun

Bao-Xun Wang

Ming-Jing Zhang

Yu Ma

Yan-Xia Zhou ( $\nabla$ zhouyx@sdu.edu.cn )

Shandong University

\section{Research Article}

Keywords: 16S rRNA gene sequence, Jeotgalibacillus kunyuensis, Novel species, Polyphasic taxonomy

Posted Date: February 7th, 2022

DOI: https://doi.org/10.21203/rs.3.rs-1311318/v1

License: (c) (i) This work is licensed under a Creative Commons Attribution 4.0 International License.

Read Full License 


\section{Abstract}

A Gram-stain-positive, orange-pigmented, rod-shaped, flagellated bacterial strain $\mathrm{T}_{12}{ }^{\top}$, was isolated from wetland soil in Kunyu Mountain Wetland in Yantai, China. This organism was able to grow at $15-40{ }^{\circ} \mathrm{C}$ (optimum $37^{\circ} \mathrm{C}$ ), at $0.0-9.0 \% \mathrm{NaCl}$ (optimum 2\%, w/v) and at pH 5.5-9.0 (optimum 8.5). Phylogenetic analysis based on $16 \mathrm{~S}$ rRNA indicated that strain $\mathrm{T} 12^{\top}$ was a member of the family Planococcaceae and it represented highly $16 \mathrm{~S}$ rRNA gene sequence similarity with Jeotgalibacillus salarius (97.6\%) and the type strain, Jeotgalibacillus marinus (96.9\%). Genome analysis revealed that the genome size was 3506682 bp and the DNA G+C content was 43.7 mol\%. Besides, the genome sequence showed 55.0$74.6 \%$ average amino acid identity values and $67.8-74.7 \%$ average nucleotide identity values between the strain $\mathrm{T} 12^{\top}$ and all the related strains. Digital DNA-DNA hybridization of strain $\mathrm{T} 12^{\top}$ with Jeotgalibacillus proteolyticus and Jeotgalibacillus marinus demonstrated $19.0 \%$ and $20.3 \%$ relatedness. Chemotaxonomic analysis showed that the sole quinone was MK-7. The predominant cellular fatty acids were iso- $\mathrm{C}_{15: 0}$, anteiso- $\mathrm{C}_{15: 0}, \mathrm{C}_{16: 1} \omega 7 \mathrm{c}$ alcohol and iso- $\mathrm{C}_{14: 0}$. The polar lipids consisted of aminolipid, phosphatidylglycerol, diphosphatidylglycerol and two unidentified phospholipids. Based on polyphasic characterization, strain $\mathrm{T} 12^{\top}$ is considered to represent a novel species, for which the name Jeotgalibacillus kunyuensis sp. nov. is proposed. The type strain is $\mathrm{T}_{12}{ }^{\top}\left(=\mathrm{KCTC} 43296^{\top}=\mathrm{MCCC}^{\circ}\right.$ $\left.1 \mathrm{~K} 07171^{\top}\right)$.

\section{Introduction}

The genus Jeotgalibacillus, which belongs to the family Planococcaceae, was first established by Yoon (Yoon et al. 2001). There are nine species in this genus at the time of writing: Jeotgalibacillus marinus (Ruger 1983, Ruger and Richter 1979), Jeotgalibacillus alimentarius (Yoon et al. 2001), Jeotgalibacillus campisalis (Yoon et al. 2004), Jeotgalibacillus salarius (Yoon et al. 2010), Jeotgalibacillus soli (Cunha et al. 2012), Jeotgalibacillus malaysiensis (Yaakop et al. 2015), Jeotgalibacillus terrae (Srinivas et al. 2016, Chen et al. 2010), Jeotgalibacillus alkaliphilus (Srinivas et al. 2016) and Jeotgalibacillus proteolyticus (Li et al. 2018). Members of the family Planococcaceae were mostly isolated from marine environments or seafood jeotgal. Most of the species were described as Gram-stain-positive; the $\mathrm{G}+\mathrm{C}$ content was around 39.3-44.0 mol\% (Yaakop et al. 2015); the major cellular fatty acids were iso- $\mathrm{C}_{15: 0}$ and anteiso- $\mathrm{C}_{15: 0}$ and the MK-7 and MK-8 were the respiratory quinone. In our study, the novel isolate $\mathrm{T} 12^{\top}$ was isolated from wetland soil, exhibiting similar characteristics as described above. The present study was proposed to demonstrate its taxonomic position throughout a polyphasic analysis.

\section{Materials And Methods}

\section{Isolation of strain $\mathrm{T} 12^{\top}$}

Strain was isolated from wetland soil collected from Kunyu Mountain Wetland in Yantai, Shandong Province, China $\left(121^{\circ} 49^{\prime} 36^{\prime \prime} \mathrm{E}, 37^{\circ} 13^{\prime} 18^{\prime \prime} \mathrm{N}\right)$. The wetland soil sample was inoculated on marine agar 2216 
(MA, Becton Dickinson) after being diluted in multiple series of gradient with sterile water. Colonies with different phenotypes were obtained after $48 \mathrm{~h}$ of incubated at $37^{\circ} \mathrm{C}$. An orange colony was obtained by repeated purified. Five reference strains: J. alimentarius JCM $10872^{\top}$, J. proteolyticus MCCC $1 \mathrm{H}^{-00228^{\top}}, \mathrm{J}$. salarius KCTC $13257^{\top}$, J. marinus DSM $1297^{\top}$ and J. campisalis JCM $11810^{\top}$, were purchased from their respective strain collection institutions. Above-mentioned strains were preserved in seawater supplemented with $15 \%(\mathrm{v} / \mathrm{v})$ glycerol at $-80^{\circ} \mathrm{C}$ for further use.

\section{Phylogenetic analysis of the 16S rRNA gene and whole genome sequencing}

The $16 \mathrm{~S}$ rRNA of strain $\mathrm{T} 12^{\top}$ was determined after being amplified by PCR with two universal primers $27 \mathrm{~F}$ (5'-AGA GTT TGA TCC TGG CTC AG-3') and 1492R (5'-GGT TAC CTT GTT ACG ACT T-3') as described previously (Zhou et al. 2016). The acquired 16S rRNA sequence was then compared with other published species using EzBioCloud (Yoon et al. 2017) and NCBI BLAST. Strain $\mathrm{T} 12^{\top}$ was discovered to be a member of the genus Jeotgalibacillus based on the 16S rRNA sequence similarity greater than $95.0 \%$ compared with all the genus-type strains. Phylogenetic trees were inferred by the neighbour-joining (Saitou and Nei 1987) and maximum-likelihood (Felsenstein 1981) using the software package MEGA version 7.0 (Kumar et al. 2016) with the Kimura two-parameter model (Kimura 1980). Bootstrap analyses of the phylogenetic trees were performed based on 1000 replicates.

\section{Genome features}

The draft genome sequence of strain $\mathrm{T} 12^{\top}$ was performed using the lllumina HiSeq-PE150 platform. De novo assembly of sequenced reads were assembled using the SOAP, Spades, and Abyss software. These operations were all implemented by Beijing Novogene Bioinformatics Technology Co, Ltd. (Beijing, China). The genes involved in metabolic pathways were analysed using the Kyoto Encyclopedia of Genes and Genomes (KEGG) databases (Kanehisa et al. 2016). Protein-encoding regions were identified and annotated with the Rapid Annotations using Subsystems Technology (RAST) server (http://rast.nmpdr.org/rast.cgi) (Aziz 2008) and the UniProtKB/Swiss-Prot (Consortium TU 2019). The secondary metabolites were undertaken by antiSMASH 5.0 (Blin et al. 2019). The DNA G+C content of strain $\mathrm{T} 12^{\top}$ was determined from the genome sequence.

Genome sequence comparisons between strain $T 12^{\top}$ and closely related strains were performed by calculating the average nucleotide identity (ANI) values and using the ANI Calculator EZ Biocloud tool (www.ezbiocloud.net/tools/ani). The average amino acid identity (AAl) calculator was carried out between strain $\mathrm{T} 12^{\top}$ and its neighbouring species (http://enve-omics.ce.gatech.edu/aai/). Digital DNADNA hybridization ( $\mathrm{dDDH}$ ) were calculated using the Genome-to-Genome Distance Calculator (GGDC) version 3.0 (Meier-Kolthoff et al. 2013).

\section{Morphology, physiology, and biochemical analysis}


Gram staining was performed as described by Moyes (Moyes et al. 2009). After incubating the bacterium on $\mathrm{MA}$ at $37^{\circ} \mathrm{C}$ for 2 days, the cell morphology and presence of flagella were observed via transmission electron microscope (Jem-1200EX; JEOL). Growth at various $\mathrm{NaCl}$ concentrations was investigated in $\mathrm{NaCl}$-free artificial seawater medium supplemented with various concentrations of $\mathrm{NaCl}$ (final concentration $0-15.0 \%$, in increments of $0.5 \%, \mathrm{w} / \mathrm{v}$ ) (Yang and Cho 2008). Growing status of strain T12 ${ }^{\top}$ at different temperatures, ranging from $4^{\circ} \mathrm{C}$ to $50^{\circ} \mathrm{C}\left(4,10,15,20,25,30,35,37,40,45\right.$ and $\left.50^{\circ} \mathrm{C}\right)$, was measured on marine broth 2216 (MB, Becton Dickinson) and the optimum growth temperature was obtained from above. The $\mathrm{pH}$ range for growth was determined on $\mathrm{MB}$, adjusted to various $\mathrm{pH}$ values ( $\mathrm{pH}$ 5.5-9.5, at intervals of $0.5 \mathrm{pH}$ units) using the following buffer systems: MES ( $\mathrm{pH} 5.5$ and 6.0), PIPES (pH 6.5 and 7.0), HEPES ( $\mathrm{pH} 7.5$ and 8.0), Tricine ( $\mathrm{pH} 8.5$ ), and CAPSO (pH 9.0 and 9.5). Anaerobic growth was tested on MA with or without $0.1 \% \mathrm{NaNO}_{3}$ under anaerobic conditions at $37^{\circ} \mathrm{C}$ for 2 weeks. Various biochemical tests, such as oxidase, hydrolysis of cellulose, agar, casein and Tween 80 were tested by procedures as described by Tindall (Tindall et al. 2007). The oxidation and fermentation test of carbohydrates were investigated using the Biolog GEN III Micro Plates and API 50CHB Fermentation Kit (bioMérieux) after growth on MA at $37^{\circ} \mathrm{C}$ for 2 days. Additional physiological tests were examined using API 20E, API 20NE and API ZYM strips (bioMérieux). Susceptibility to antibiotics was carried out on MA plates with discs (Tianhe) containing various antibiotics for 3 days at $37^{\circ} \mathrm{C}$.

\section{Chemotaxonomic characterisation}

To determine the chemotaxonomic characteristics, strain $\mathrm{T} 12^{\top}$ and the reference strains were cultured in MB at optimum temperature for 2 days. Fatty acid extraction and analyses were performed by Sherlock Microbial Identification System (MIDI) (Sawant et al. 2015) with the TSBA6.0 database. Detection of respiratory quinone was completed with High Performance Liquid Chromatography (HPLC) (Hiraishi et al. 1996). Polar lipid analysis was performed by the Marine Culture Collection of China (MCCC), Xiamen, Fujian Province, China.

\section{Results And Discussion}

\section{Phylogenetic analysis}

The almost-complete 16S rRNA gene sequence of strain $\mathrm{T}^{\top} 2^{\top}(1514 \mathrm{bp})$ was determined and confirmed with the draft genome sequence. Phylogenetic analysis based on 16S rRNA gene sequences revealed that strain $\mathrm{T} 12^{\top}$ belonged to the genus Jeotgalibacillus, within the family Planococcaceae, sharing highly similarity with $\mathrm{J}$. salarius ASL-1 ${ }^{\top}$ (97.6\%). Phylogenetic analysis based on $16 \mathrm{~S}$ rRNA gene sequences showed that strain $\mathrm{T} 12^{\top}$ was in the same cluster as J. campisalis SF- $57^{\top}, \mathrm{J}$. proteolyticus $22-7^{\top}, J$. marinus strain $581^{\top}$ and $J$. soli $\mathrm{Pg}^{\top}$ in the neighbour-joining tree (Fig. 1), which was also shown in the maximum-likelihood tree (Supplementary Fig. S1). The low 16S rRNA gene sequence similarities and phylogenetic location indicated that strain $\mathrm{T} 12^{\top}$ should be located within the genus Jeotgalibacillus as a novel species. 


\section{Genome features}

General features of strain $\mathrm{T} 12^{\top}$ genome were summarized in Supplementary Table S1. The genome size of strain $\mathrm{T} 12^{\top}$ was $3506682 \mathrm{bp}$, which contained 4066 predicted genes of 26 scaffolds and the depth coverage of sequencing was 330x. The N50 and N90 value was $933824 \mathrm{bp}$ and $135228 \mathrm{bp}$. There were $5 S$ rRNAs of 6 , tRNAs of 67 and sRNAs of 2 . The DNA G+C content of strain $T 12^{\top}$ was $43.7 \mathrm{~mol} \%$, which was within the range of DNA G+C contents for species of the genus Jeotgalibacillus (39-44 mol\%) as previously reported.

According to Cluster of Orthologous Groups (COG), the genome contained several genes coding for amino acid transport and metabolism, transcription, carbohydrate transport and metabolism, signal transduction mechanisms, inorganic ion transport and metabolism and a number of unknown functions, which played a role in several aspects of cell live activities (Supplementary Fig. S2).

Strain $\mathrm{T} 12^{\top}$ contained 2041 genes related to the KEGG metabolic pathway, including metabolism (68.3\%), environmental information processing (9.9\%), genetic information processing (9.0\%), cellular processes (7.5\%), human diseases (3.1\%) and organismal systems (2.2\%) (Supplementary Fig. S3). RAST identified 915 subsystems from the strain $\mathrm{T} 12^{\top}$, in which amino acids and derivatives (250) had the highest counts, followed by carbohydrates (194) and protein metabolism (179) (Supplementary Fig. S4).

Furthermore, strain $\mathrm{T} 12^{\top}$ contained one or more polar or peripheral flagella and 62 genes related to cell motility were found in the genome as well. In agreement with phenotypic data, a flagellar assembly pathway (02040) was found, which annotated genes coding for flagellar related proteins (flagellar basalbody rod protein FlgG; flagellar secretion chaperone FliS; flagellin; chemotaxis protein MotA and MotB). Besides, in carotenoid synthesis, a complete pathway synthesized from phytoene to lycopene was discovered. Among them, genes encoding for carotenoid biosynthesis such as crtt was found in strain $\mathrm{T} 12^{\top}$, which may be responsible for the phenotypic colour of strain $\mathrm{T} 12^{\top}$ (Kallscheuer et al. 2019).

The results of the antiSMASH analysis showed that strain $\mathrm{T} 12^{\top}$ had three biosynthetic gene clusters (BGCs) in its genome including lasso peptide (paeninodin), terpene (carotenoid) and siderophore cluster. The terpene biosynthetic gene cluster, which may be related to the colour pigmentation associated with the bacterial colony (Paniagua-Michel et al. 2012), was detected in most species of the genus Jeotgalibacillus.

ANI values between strain $\mathrm{T} 12^{\top}$ and the type strains of recognized Jeotgalibacillus species were less than $74.9 \%$ (Supplementary Table S2), significantly lower than the threshold value of $95 \%$ for species and genus (Richter and Rossello-Mora 2009). AAI values (55.0-74.6\%) were lower than $75 \%$ with all the closely related species, well below the proposed cut-off values for genus delineation in the family Planococcaceae. The dDDH relatedness comparison with the draft genome for strain $\mathrm{T}_{1}{ }^{\top}$ showed low percentage (19.0-20.6\%) similarities with all the related species and were much lower than the boundary 
(70.0\%) for species identification. $\mathrm{ANI}, \mathrm{AAl}$ and $\mathrm{dDDH}$ analysis results suggest that strain $\mathrm{T}_{12}{ }^{\top}$ is a new species of the genus Jeotgalibacillus.

\section{Morphology and Phenotypic characterization}

Cells were Gram-stain-positive, flagellated, rod-shaped (0.4-0.6 $\mu \mathrm{m}$ in width, 1.6-3.4 $\mu \mathrm{m}$ in length) (Supplementary Fig. S5). Colonies were circular to slightly irregular, flat to raised, smooth, orange coloured and $0.8-1.4 \mathrm{~mm}$ in diameter after incubation on MA for 2 days at $37^{\circ} \mathrm{C}$. Strain $\mathrm{T} 12^{\top}$ had one or more polar or peritrichous flagella, which was similar to the reference strains. The novel strain was found to grow at a temperature range of $15-40^{\circ} \mathrm{C}$ (optimum temperature $37^{\circ} \mathrm{C}$ ), $\mathrm{pH} 5.5-9.0$ (optimum pH of 8.5) and $\mathrm{NaCl}$ tolerance of $0.0-9.0 \%$ (optimum $2 \%, w / v$ ). It could grow at $0 \% \mathrm{NaCl}$ condition, which was similar to the related strains. Strain $T 12^{\top}$ differed from the closely related strain $\mathrm{J}$. salarius $\mathrm{ASL}-1^{\top}$ with respect to numerous phenotypic characteristics, such as lipase (C14), alkaline phosphatase, trypsin and a-chymotrypsin activities. Strain $\mathrm{T} 12^{\top}$ showed negative for $\mathrm{H}_{2} \mathrm{~S}$, starch, alginate, cellulose, oxidase and catalase. Besides, it was sensitive to penicillin, ampicillin cefazolin, amikacin, gentamicin, erythromycin, norfloxacin, ciprofloxacin, compound sulfamethoxazole and chloramphenicol. Other characteristics of strain $\mathrm{T} 12^{\top}$ are presented in the species description and Table 1.

Table 1 Differential phenotypic characteristics of strain $\mathrm{T} 12^{\top}$ and other closely related members of the genus Jeotgalibacillus. 


\begin{tabular}{|c|c|c|c|c|c|c|}
\hline Characteristic & 1 & 2 & 3 & 4 & 5 & 6 \\
\hline Oxidase & - & + & - & - & + & + \\
\hline \multicolumn{7}{|l|}{$\begin{array}{l}\text { Growth range } \\
\text { (optimum) }\end{array}$} \\
\hline $\mathrm{NaCl}(\mathrm{w} / \mathrm{v}, \%)$ & $0-9 \%(2 \%)$ & $\begin{array}{l}0-20 \% \\
(3- \\
12 \%)\end{array}$ & $\begin{array}{l}0-15 \%(2- \\
5 \%)\end{array}$ & $\begin{array}{l}0-10 \% \\
(2 \%)\end{array}$ & $\begin{array}{l}0-7 \% \\
(3- \\
3.5 \%)\end{array}$ & $\begin{array}{l}0-18 \% \\
(2 \%)\end{array}$ \\
\hline $\begin{array}{l}\text { Temperature } \\
\left({ }^{\circ} \mathrm{C}\right)\end{array}$ & $15-40^{\circ} \mathrm{C}\left(37^{\circ} \mathrm{C}\right)$ & $\begin{array}{l}10-45 \\
{ }^{\circ} \mathrm{C}(30- \\
\left.35{ }^{\circ} \mathrm{C}\right)\end{array}$ & $\begin{array}{l}4-39{ }^{\circ} \mathrm{C}(30 \\
\left.{ }^{\circ} \mathrm{C}\right)\end{array}$ & $\begin{array}{l}10-40 \\
{ }^{\circ} \mathrm{C}(33 \\
\left.{ }^{\circ} \mathrm{C}\right)\end{array}$ & $\begin{array}{l}5-30 \\
{ }^{\circ} \mathrm{C}(12- \\
\left.23^{\circ} \mathrm{C}\right)\end{array}$ & $\begin{array}{l}4-40^{\circ} \mathrm{C} \\
\left(30^{\circ} \mathrm{C}\right)\end{array}$ \\
\hline \multicolumn{7}{|l|}{ Hydrolysis of } \\
\hline Gelatin & + & + & - & + & + & - \\
\hline Starch & - & - & + & - & - & - \\
\hline \multicolumn{7}{|l|}{ Acids from } \\
\hline Mannitol & - & + & + & - & - & + \\
\hline D-Mannose & - & - & - & - & + & - \\
\hline \multicolumn{7}{|l|}{$\begin{array}{l}\text { Enzyme } \\
\text { activity }\end{array}$} \\
\hline Esterase (C4) & + & + & - & + & - & + \\
\hline $\begin{array}{l}\beta- \\
\text { Galactosidase }\end{array}$ & + & + & + & + & - & - \\
\hline a-Glucosidase & + & + & - & - & - & - \\
\hline $\begin{array}{l}\text { Predominant } \\
\text { menaquinone }\end{array}$ & MK-7 & $\begin{array}{l}\text { MK-7, } \\
\text { MK-8 }\end{array}$ & MK-7 & MK-7 & MK-7 & $\begin{array}{l}\text { MK-7, } \\
\text { MK-8 }\end{array}$ \\
\hline $\begin{array}{l}\text { Major fatty } \\
\text { acid }\end{array}$ & $\begin{array}{l}\text { iso- } \mathrm{C}_{15: 0} \text {, anteiso- } \\
\mathrm{C}_{15: 0}, \mathrm{C}_{16: 1} \omega 7 \mathrm{c} \\
\text { alcohol, iso- } \mathrm{C}_{14: 0}\end{array}$ & $\begin{array}{l}\text { iso- } \\
\mathrm{C}_{15: 0} \\
\text { anteiso- } \\
\mathrm{C}_{15: 0}\end{array}$ & $\begin{array}{l}\text { anteiso- } \mathrm{C}_{15: 0} \\
\mathrm{C}_{16: 1} \mathrm{~W} 7 \mathrm{c} \\
\text { alcohol, iso- } \\
\mathrm{C}_{14: 0}\end{array}$ & $\begin{array}{l}\text { anteiso- } \\
\mathrm{C}_{15: 0} \\
\text { iso- } \\
\mathrm{C}_{15: 0}\end{array}$ & $\begin{array}{l}\text { anteiso- } \\
\mathrm{C}_{15: 0} \\
\text { iso- } \\
\mathrm{C}_{15: 0}\end{array}$ & $\begin{array}{l}\text { anteiso- } \\
\mathrm{C}_{15: 0} \\
\mathrm{C}_{16: 1} \omega 7 \mathrm{c} \\
\text { alcohol }\end{array}$ \\
\hline $\begin{array}{l}\text { DNA G+C } \\
\text { content (\%) }\end{array}$ & 43.7 & 44 & 41.8 & 41.6 & 39.3 & 42.9 \\
\hline
\end{tabular}

Strains: 1, strain $\mathrm{T} 12^{\top} ; 2$, J. alimentarius JCM $10872^{\top} ; 3$, J. campisalis JCM $11810^{\top} ;$, J. proteolyticus $1 \mathrm{H}^{2} 228^{\top}$; 5, J. marinus DSM $1297^{\top}$; 6 , J. salarius KCTC $13257^{\top}$. +, Positive; -, negative; w, weak. All data from this study except DNA G+C contents of the related strains, which were from the original species description: 2 (Yoon et al. 2010, Yoon et al. 2001), 3 (Cunha et al. 2012, Yaakop et al. 2015, Yoon et al. 2010), 4 (Li et al. 2018), 5 (Yoon et al. 2010, Yoon et al. 2001), 6 (Yoon et al. 2010).

\section{Chemotaxonomy}


The major polar lipids of strain $T 12^{\top}$ were phosphatidylglycerol (PG), diphosphatidylglycerol (DPG) and phosphatidylcholine (PC) (Supplementary Fig. S6); these were different from J. proteolyticus 22-7 ${ }^{\top}$ (aminophospholipid, phosphatidylethanolamine, phosphatidylglycerol and diphosphatidylglycerol) (Li et al. 2018). The predominant cellular fatty acids of strain $T 12^{\top}$ were summed iso- $\mathrm{C}_{15: 0}(28.4 \%)$, anteiso$C_{15: 0}(19.6 \%), C_{16: 1} \omega 7 \mathrm{c}$ alcohol $(13.0 \%)$ and iso- $C_{14: 0}(10.1 \%)$, which were similar to those of the related strains and the detailed information was shown in Table 2 . The sole quinone of strain $\mathrm{T} 12^{\top}$ was identified as MK-7, which was similar to that of the other members of the genus Jeotgalibacillus. These chemotaxonomic data further confirm that strain $\mathrm{T} 12^{\top}$ belongs to the genus Jeotgalibacillus.

Table 2 Cellular fatty acid compositions of strain $\mathrm{T}_{1} 2^{\top}$ and the closest relatives. 


\begin{tabular}{|c|c|c|c|c|c|c|}
\hline Fatty acid & 1 & 2 & 3 & 4 & 5 & 6 \\
\hline \multicolumn{7}{|l|}{ Saturated fatty acids } \\
\hline $\mathrm{C}_{10: 0}$ & - & - & TR & 1.99 & - & - \\
\hline$C_{14: 0}$ & 1.31 & $\mathrm{TR}$ & 1.65 & 1.05 & 1.19 & 1.54 \\
\hline$C_{16: 0}$ & 2.30 & $\mathrm{TR}$ & 2.94 & 1.68 & 2.44 & 5.37 \\
\hline $\mathrm{C}_{18: 0}$ & $\mathrm{TR}$ & $\mathrm{TR}$ & 1.63 & $\mathrm{TR}$ & 1.37 & 3.67 \\
\hline \multicolumn{7}{|l|}{ Unsaturated } \\
\hline$C_{16: 1} \omega 7 c$ alcohol & 13.00 & 5.01 & 18.32 & 4.98 & 9.10 & 14.22 \\
\hline$C_{16: 1} \omega 11 c$ & 2.24 & 2.04 & 2.06 & 2.84 & 1.84 & 2.02 \\
\hline$C_{18: 1} \omega 9 c$ & $\mathrm{TR}$ & - & 1.25 & - & TR & 2.51 \\
\hline \multicolumn{7}{|l|}{ Branched fatty acids } \\
\hline iso- $\mathrm{C}_{14: 0}$ & 10.10 & 1.60 & 16.26 & 1.47 & 8.83 & 9.09 \\
\hline iso- $\mathrm{C}_{15: 0}$ & 28.40 & 52.22 & 3.20 & 15.98 & 19.61 & 8.57 \\
\hline anteiso- $\mathrm{C}_{15: 0}$ & 19.63 & 14.65 & 31.05 & 39.15 & 31.19 & 30.62 \\
\hline iso- $\mathrm{C}_{16: 0}$ & 6.56 & $\mathrm{TR}$ & 7.23 & 2.04 & 6.08 & 4.69 \\
\hline iso- $\mathrm{C}_{17: 0}$ & 1.63 & 2.17 & $\mathrm{TR}$ & 4.61 & 1.54 & $\mathrm{TR}$ \\
\hline anteiso- $\mathrm{C}_{17: 0}$ & 3.92 & 2.08 & 4.13 & 8.44 & 4.88 & 5.72 \\
\hline iso- $C_{17: 1} \omega 10 c$ & 1.06 & 8.10 & $\mathrm{TR}$ & 2.66 & 1.33 & $\mathrm{TR}$ \\
\hline Summed Feature ${ }^{a}$ & $\mathrm{TR}$ & $\mathrm{TR}$ & $\mathrm{TR}$ & 1.04 & $\mathrm{TR}$ & $\mathrm{TR}$ \\
\hline Summed Feature ${ }^{b}$ & 2.34 & 5.06 & 3.97 & 5.36 & 4.83 & 3.51 \\
\hline Summed Feature8c & $\mathrm{TR}$ & TR & $\mathrm{TR}$ & $\mathrm{TR}$ & TR & 2.22 \\
\hline
\end{tabular}

Strains: 1, strain $\mathrm{T}_{12}^{\top} ; 2$, J. alimentarius JCM $10872^{\top} ; 3$, J. campisalis JCM $11810^{\top} ; 4$, J. proteolyticus

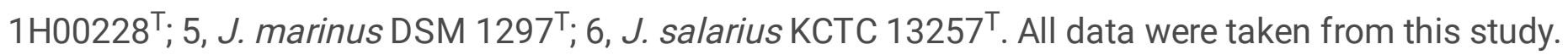
Major components are indicated with bold text. TR, Traces $(<1.0 \%) ;-$, not detected. Fatty acids amounting to $<1.0 \%$ of the total fatty acids in both strains are not shown.

asummed feature $3, \mathrm{C}_{16: 1} \omega 7 \mathrm{c}$ and/or $\mathrm{C}_{16: 1} \omega 6 \mathrm{c}$ 
bSummed feature 4, iso- $\mathrm{C}_{17: 1}$ and/or anteiso- $\mathrm{C}_{17: 1} \mathrm{~B}$

'Summed feature $8, \mathrm{C}_{18: 1} \omega 7 \mathrm{c}$ and/or $\mathrm{C}_{18: 1} \omega 6 \mathrm{c}$

\section{Conclusion}

According to polyphasic taxonomy analyses, strain $\mathrm{T} 12^{\top}$ should be assigned to the genus Jeotgalibacillus as a new species, for which the name Jeotgalibacillus kunyuensis sp. nov. is proposed.

Description of Jeotgalibacillus kunyuensis sp. nov.

Jeotgalibacillus kunyuensis (kun.yu.en'sis. N.L. masc. adj. kunyuensis of or belonging to Kunyu Mountain Wetland, China, the geographical origin of the type strain of the species)

Cells are Gram-stain-positive, catalase-negative, oxidase-negative and rod-shaped $(0.4-0.6 \mu \mathrm{m}$ wide and 1.6-3.4 $\mu \mathrm{m}$ long). Colonies are circular to slightly irregular, orange coloured, flat to raised and 0.8-1.4 mm in diameter on MA plates after 2 days of incubation at $37^{\circ} \mathrm{C}$. Growth occurs in the range of $15-40^{\circ} \mathrm{C}$ and $\mathrm{pH} 5.5-9.0$, with optimal at $37^{\circ} \mathrm{C}$ and $\mathrm{pH}$ 8.5. The optimal $\mathrm{NaCl}$ concentration is $2 \%(\mathrm{w} / \mathrm{v})$. Cells degrade gelatin and but not agar, starch, $\mathrm{H}_{2} \mathrm{~S}$, alginate or cellulose. In the API system, alkaline phosphatase, trypsin, a-chymotrypsin, naphthol-AS-BI-phosphohydrolase, $\beta$-galactosidase, esterase (C4), esterase lipase (C8) and lipase (C14) are present, but acid phosphatase, $\alpha$-galactosidase, $\beta$-glucuronidase, $\beta$ glucosaccharase, leucine arylamidase and $\mathrm{N}$-acetyl- $\beta$-glucosaminidase are absent. The sole quinone is MK-7. Predominant fatty acids $(>10 \%)$ were observed as iso- $\mathrm{C}_{15: 0}(28.4 \%)$, anteiso- $\mathrm{C}_{15: 0}(19.6 \%)$, $\mathrm{C}_{16: 1} \omega 7 \mathrm{c}$ alcohol $(13.0 \%)$ and iso- $\mathrm{C}_{14: 0}(10.1 \%)$. The polar lipids consist of aminolipid, phosphatidylglycerol, diphosphatidylglycerol, phosphatidylcholine and two unidentified phospholipids. The DNA G+C content is $43.7 \mathrm{~mol} \%$. The strain $\mathrm{T} 12^{\top}$ was sensitive to penicillin, ampicillin cefazolin, amikacin, gentamicin, erythromycin, norfloxacin, ciprofloxacin, compound sulfamethoxazole and chloramphenicol.

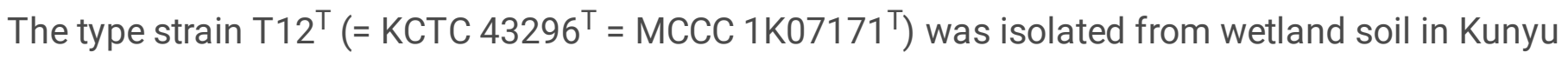
Mountain Wetland in Yantai, Shandong Province, China.

The GenBank accession number for the $16 \mathrm{~S}$ rRNA gene sequence of strain $\mathrm{T}^{\top} 2^{\top}$ is MW527064 and the number for the whole genome sequence is JACNMS000000000.

\section{Abbreviations}

AAl Average Amino Acid Identity

AL aminolipid

ANI Average Nucleotide Identity 
BGCs Biosynthetic Gene Clusters

COG Cluster of Orthologous Groups

dDDH digital DNA-DNA Hybridization

DPG diphosphatidylglycerol

GGDC Genome-to-Genome Distance Calculator

HPLC High Performance Liquid Chromatography

KCTC Korean Collection for Type Cultures

KEGG Kyoto Encyclopedia of Genes and Genomes

MA Marine agar 2216

MB Marine broth 2216

MEGA Molecular Evolutionary Genetics Analysis

MIDI Microbial Identification System

MCCC Marine Culture Collection of China

PC phosphatidylcholine

PG phosphatidylglycerol

RAST Rapid Annotations using Subsystems Technology

\section{Declarations}

\section{Acknowledgements}

We are very grateful to Prof. Aharon Oren for his advice on naming the species.

Authors' contributions HNJ drafted the manuscript. BXW, STY, HNJ and YM performed isolation, deposition and identification. STY, BXW and MJZ performed genome analysis. STY and YXZ revised the manuscript. YXZ designed all the experiments and supervised the manuscript.

\section{Funding}

This work was supported by the National Natural Science Foundation of China (31700116), the Natural Science Foundation of Shandong Province (ZR2017MC019), the China Postdoctoral Science Foundation (2017M62218), and the Key Science and Technology Program of Weihai (1070413421511). 


\section{Data availability}

All data generated or analysed during this study are included in this published article, its supplementary information files and GenBank/EMBL/DDBJ. The GenBank/EMBL/DDBJ accession number for the $16 \mathrm{~S}$ rRNA gene sequence of strain $T 12^{\top}$ is MW527064 and the number for the whole genome sequence is JACNMS000000000. Supplementary figures and Supplementary tables are available with the online version of this paper.

Ethical approval This article does not contain any studies with human participants or animals performed by any of the authors.

Conflict of interest Authors declare that there is no conflict of interest.

The GenBank/EMBL/DDBJ accession number for the 16S rRNA gene sequence of strain $\mathrm{T}^{1}{ }^{\mathrm{T}}$ is MW527064 and the number for the whole genome sequence is JACNMS000000000.

\section{References}

1. Aziz RK (2008) The RAST Server: Rapid Annotations using Subsystems Technology. BMC Genomics 9:75. https://doi.org/10.1186/1471-2164-9-75

2. Blin K, Shaw S, Steinke K, Villebro R, Ziemert N, Lee SY, Medema MH, Weber T (2019) antiSMASH 5.0: updates to the secondary metabolite genome mining pipeline. Nucleic Acids Res 47:W81-W87. https://doi.org/10.1093/nar/gkz310

3. Chen YG, Peng DJ, Chen QH, Zhang YQ, Tang SK, Zhang DC, Peng QZ, Li WJ (2010) Jeotgalibacillus soli sp. nov., isolated from non-saline forest soil, and emended description of the genus Jeotgalibacillus. Antonie Van Leeuwenhoek 98:415-421. https://doi.org/10.1007/s10482-010-9455$\mathrm{z}$

4. Consortium TU (2019) UniProt: a worldwide hub of protein knowledge. Nucleic Acids Res 47:D506D515. https://doi.org/10.1093/nar/gky1049

5. Cunha S, Tiago I, Paiva G, Nobre F, Da Costa MS, Verissimo A (2012) Jeotgalibacillus soli sp. nov., a Gram-stain-positive bacterium isolated from soil. Int J Syst Evol MicroBiol 62:608-612. https://doi.org/10.1099/ijs.0.028878-0

6. Felsenstein J (1981) Evolutionary trees from DNA sequences: A maximum likelihood approach. J Mol Evol 17:368-376. https://doi.org/10.1007/BF01734359

7. Hiraishi A, Ueda Y, Ishihara J, Mori T (1996) Comparative lipoquinone analysis of influent sewage and activated sludge by high-performance liquid chromatography and photodiode array detection. $\mathrm{J}$ Gen Appl Microbiol 42:457-469. https://doi.org/10.2323/jgam.42.457

8. Kallscheuer N, Moreira C, Airs R, Llewellyn CA, Wiegand S, Jogler C, Lage OM (2019) Pink- and orange-pigmented Planctomycetes produce saproxanthin-type carotenoids including a rare C45 carotenoid. Environ Microbiol Rep 11:741-748. https://doi.org/10.1111/1758-2229.12796 
9. Kanehisa M, Sato Y, Kawashima M, Furumichi M, Tanabe M (2016) KEGG as a reference resource for gene and protein annotation. Nucleic Acids Res 44:D457-D462.

https://doi.org/10.1093/nar/gkv1070

10. Kimura M (1980) A simple method for estimating evolutionary rates of base substitutions through comparative studies of nucleotide sequences. J Mol Evol 16:111-120. https://doi.org/10.1007/BF01731581

11. Kumar S, Stecher G, Tamura K (2016) Mol Biol Evol 33:1870-1874. https://doi.org/10.1093/molbev/msw054. MEGA7: Molecular Evolutionary Genetics Analysis Version 7.0 for Bigger Datasets

12. Li Y, Zhang ZP, Xu ZX, Fang DB, Wang ET, Shao S, Du ZJ, Liu W, Xie ZH (2018) Jeotgalibacillus proteolyticus sp. nov., a protease-producing bacterium isolated from ocean sediments. Int J Syst Evol MicroBiol 68:3790-3795. https://doi.org/10.1099/ijsem.0.003060

13. Meier-Kolthoff JP, Auch AF, Klenk HP, Goker M (2013) Genome sequence-based species delimitation with confidence intervals and improved distance functions. BMC Bioinformatics 14:14. https://doi.org/10.1186/1471-2105-14-60

14. Moyes RB, Reynolds J, Breakwell DP (2009) Differential staining of bacteria: gram stain. Curr Protoc Microbiol Appendix 3. https://doi.org/10.1002/9780471729259.mca03cs15. Appendix 3C

15. Paniagua-Michel J, Olmos-Soto J, Ruiz MA (2012) Pathways of carotenoid biosynthesis in bacteria and microalgae. Methods Mol Biol 892:1-12. https://doi.org/10.1007/978-1-61779-879-5_1

16. Richter M, Rossello-Mora R (2009) Shifting the genomic gold standard for the prokaryotic species definition. Proc Natl Acad Sci USA 106:19126-19131. https://doi.org/10.1073/pnas.0906412106

17. Ruger HJ (1983) Differentiation of Bacillus globisporus, Bacillus marinus comb. nov., Bacillus aminovorans, and Bacillus insolitus. International Journal of Systematic Bacteriology 33:157-161. https://doi.org/10.1099/00207713-33-2-157

18. Ruger HJ, Richter G (1979) Bacillus globisporus subsp. marinus subsp. nov. International Journal of Systematic Bacteriology 29:196-203. https://doi.org/10.1099/00207713-29-3-196

19. Saitou N, Nei M (1987) The neighbor-joining method: a new method for reconstructing phylogenetic trees. Mol Biol Evol. https://doi.org/10.1093/oxfordjournals.molbev.a040454. :406

20. Sawant SS, Salunke BK, Kim BS (2015) A rapid, sensitive, simple plate assay for detection of microbial alginate lyase activity. Enzym Microb Technol 77:8-13. https://doi.org/10.1016/j.enzmictec.2015.05.003

21. Srinivas A, Divyasree B, Sasikala C, Tushar L, Bharti D, Ramana CV (2016) Description of Jeotgalibacillus alkaliphilus sp. nov., isolated from a solar salt pan, and Jeotgalibacillus terrae sp. nov., a name to replace 'Jeotgalibacillus soli' Chen. 2010. International Journal of Systematic and Evolutionary Microbiology 66:5167-5172. https://doi.org/10.1099/ijsem.0.001491

22. Tindall BJ, Sikorski J, Smibert RA, Krieg NRJaSOM (2007) \& Phenotypic Characterization and the Principles of Comparative Systematics. Methods for general and molecular microbiology: pp 330393. https://doi.org/10.1128/9781555817497.ch15 
23. Yaakop AS, Chan KG, Ee R, Kahar UM, Kon WC, Goh KM (2015) Isolation of Jeotgalibacillus malaysiensis sp. nov from a sandy beach, and emended description of the genus Jeotgalibacillus. Int J Syst Evol MicroBiol 65:2215-2221. https://doi.org/10.1099/ijs.0.000242

24. Yang SJ, Cho JC (2008) Gaetbulibacter marinus sp. nov., isolated from coastal seawater, and emended description of the genus Gaetbulibacter. Int J Syst Evol MicroBiol 58:315-318. https://doi.org/10.1099/ijs.0.65382-0

25. Yoon JH, Kang SJ, Schumann P, Oh TKJIJOS, Microbiology E (2010) Jeotgalibacillus salarius sp. nov., isolated from a marine saltern, and reclassification of Marinibacillus marinus and Marinibacillus campisalis as Jeotgalibacillus marinus comb. nov. and Jeotgalibacillus campisalis comb. nov., respectively. International Journal of Systematic and Evolutionary Microbiology 60:15. https://doi.org/10.1099/ijs.0.008318-0

26. Yoon JH, Kim IG, Schumann P, Oh TK, Park YH (2004) Marinibacillus campisalis sp. nov., a moderate halophile isolated from a marine solar saltern in Korea, with emended description of the genus Marinibacillus. Int J Syst Evol MicroBiol 54:1317-1321. https://doi.org/10.1099/ijs.0.02779-0

27. Yoon JH, Weiss N, Lee KC, Lee IS, Kang KH, Park YH (2001) Jeotgalibacillus alimentarius gen. nov., sp. nov., a novel bacterium isolated from jeotgal with L-lysine in the cell wall, and reclassification of Bacillus marinus Ruger 1983 as Marinibacillus marinus gen. nov., comb. nov. Int J Syst Evol MicroBiol 51:2087-2093. https://doi.org/10.1099/00207713-51-6-2087

28. Yoon SH, Ha SM, Kwon S, Lim J, Kim Y, Seo H, Chun J (2017) Introducing EzBioCloud: a taxonomically united database of $16 \mathrm{~S}$ rRNA gene sequences and whole-genome assemblies. Int $\mathrm{J}$ Syst Evol MicroBiol 67:1613-1617. https://doi.org/10.1099/ijsem.0.001755

29. Zhou YX, Du ZJ, Chen GJ (2016) Seonamhaeicola algicola sp. nov., a complex-polysaccharidedegrading bacterium isolated from Gracilaria blodgettii, and emended description of the genus Seonamhaeicola. Int J Syst Evol Microbiol 66:2064-2068. https://doi.org/10.1099/ijsem.0.000991

\section{Figures}




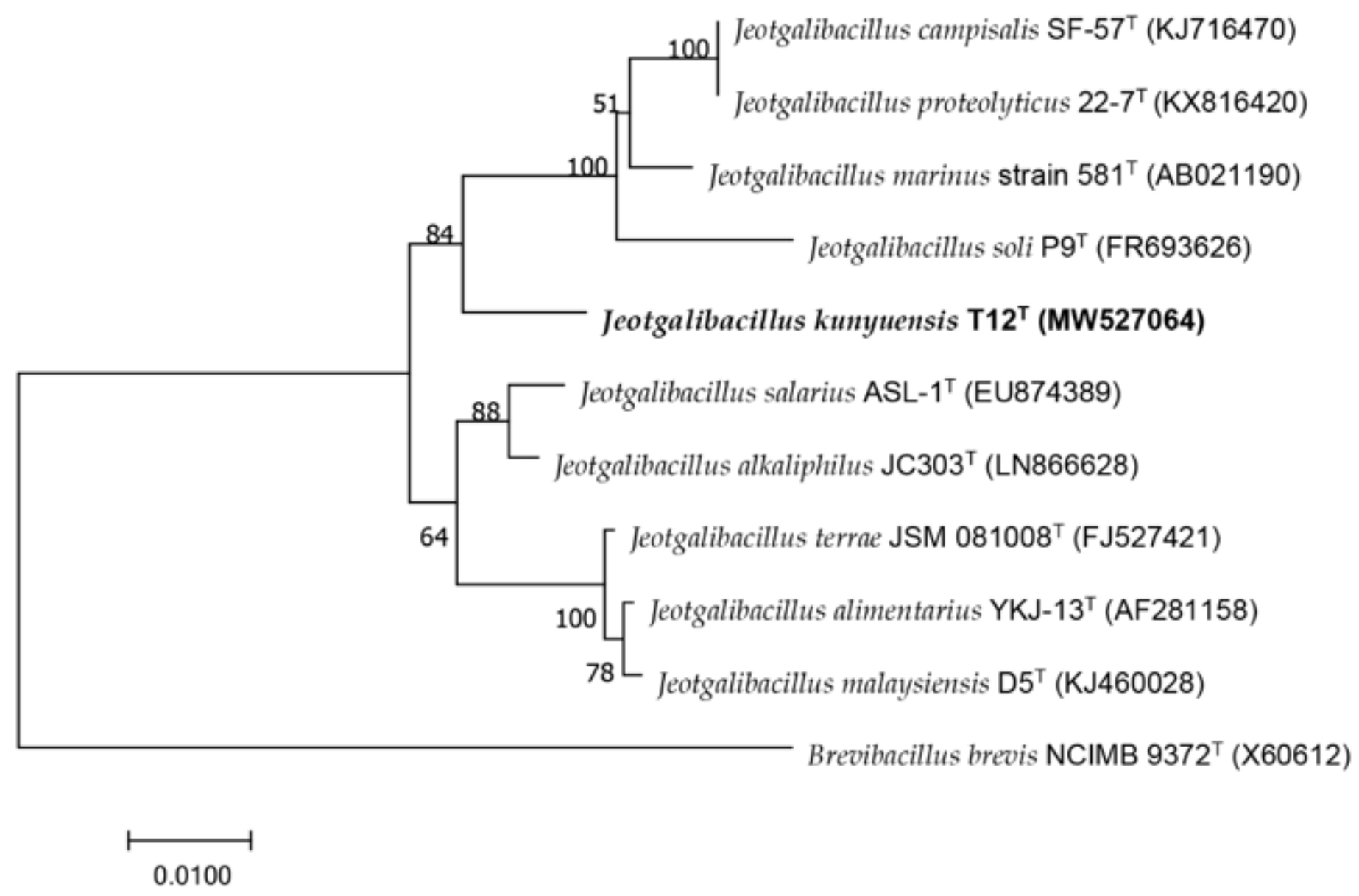

\section{Figure 1}

Neighbour-joining tree based on 16S rRNA gene sequences showing the phylogenetic position of strain $\mathrm{T} 12^{\top}$ and other related taxa. Bar, 0.01 substitution per nucleotide position. Bootstrap values were evaluated with 1000 replicates and values above $50 \%$ are shown.

\section{Supplementary Files}

This is a list of supplementary files associated with this preprint. Click to download.

- AuthorChecklist2019.pdf

- SupplementaryInformation.docx 